\title{
Noninvasive Brain Stimulation for Parkinson's Disease and Dystonia
}

\author{
Allan D. Wu, ${ }^{* \dagger}$ Felipe Fregni, ${ }^{\ddagger \S}$ David K. Simon, ${ }^{\neq \$}$ Choi Deblieck, ${ }^{* \dagger}$ and \\ Alvaro Pascual-Leone ${ }^{\ddagger \S \Phi}$ \\ *Department of Neurology and ${ }^{\dagger}$ Ahmanson-Lovelace Brain Mapping Center, University of California, Los Angeles, California \\ 90095; ${ }^{\ddagger}$ Department of Neurology, Beth Israel Deaconess Medical Center, Boston, Massachusetts 02215; ${ }^{\S}$ Berenson-Allen \\ Center for Noninvasive Brain Stimulation, Beth Israel Deaconess Medical Center and Harvard Medical School, Boston, \\ Massachusetts 02215; and "Institut Guttmann for Neurorehabilitation, Universitat Autònoma, Barcelona, Spain
}

\begin{abstract}
Summary: Repetitive transcranial magnetic stimulation (rTMS) and transcranial direct current stimulation (tDCS) are promising noninvasive cortical stimulation methods for adjunctive treatment of movement disorders. They avoid surgical risks and provide theoretical advantages of specific neural circuit neuromodulation. Neuromodulatory effects depend on extrinsic stimulation factors (cortical target, frequency, intensity, duration, number of sessions), intrinsic patient factors (disease process, individual variability and symptoms, state of medication treatment), and outcome measures. Most studies to date have shown beneficial effects of rTMS or tDCS on clinical symptoms in Parkinson's disease (PD) and support the notion of spatial specificity to the effects on motor and nonmotor symptoms. Stimulation parameters have varied widely, however, and
\end{abstract}

some studies are poorly controlled. Studies of rTMS or tDCS in dystonia have provided abundant data on physiology, but few on clinical effects. Multiple mechanisms likely contribute to the clinical effects of rTMS and tDCS in movement disorders, including normalization of cortical excitability, rebalancing of distributed neural network activity, and induction of dopamine release. It remains unclear how to individually adjust rTMS or tDCS factors for the most beneficial effects on symptoms of PD or dystonia. Nonetheless, the noninvasive nature, minimal side effects, positive effects in preliminary clinical studies, and increasing evidence for rational mechanisms make rTMS and tDCS attractive for ongoing investigation. Key Words: Parkinson's disease, dystonia, transcranial magnetic stimulation, transcranial direct current stimulation, cortical stimulation.

\section{INTRODUCTION}

Although traditional neurologic nosology broadly classifies movement disorders, such as Parkinson's disease (PD) and dystonia, as basal ganglia disorders, a single localization does not explain the breadth of phenomenology or pathophysiology of these disorders. ${ }^{1}$ Furthermore, the traditional nosology also fails to capture the impact of disease at the individual level. For example in PD patients, expression of symptoms of slowness of movement, unsteady gait, tremor, forgetfulness, depressed mood, or attentional problems and disability vary greatly from individual to individual. This individual variability is due in part to individual differences (ge-

\footnotetext{
Address correspondence and reprint requests to: Alvaro PascualLeone, M.D., Ph.D., Berenson-Allen Center for Noninvasive Brain Stimulation, Beth Israel Deaconess Medical Center, 330 Brookline Avenue, KS 158, Boston, MA 02215. E-mail: apleone@bidmc. harvard.edu.
}

netic and otherwise) and in part to variability in the mechanisms or extent of injury and the capacity of the organism to cope with it. Thus, identification of neural dysfunction within a given patient, and thereby individualizing therapy, may provide a more direct and powerful therapeutic target than working simply from a given diagnostic label. Advances since the 1960s have emphasized diverse mechanisms as contributing to the pathophysiology of movement disorders, such as depletion of neurotransmitters (e.g., dopamine), altered network loops between the basal ganglia and cortical targets, and abnormal cortical plasticity. Based on the concepts involved, a wide range of current treatment options have been developed, including medications, botulinum toxin, and deep brain stimulation (DBS). ${ }^{2,3}$

In spite of such advances, limitations in current therapies remain. Dopamine replacement medications are an effective cornerstone of current medical management of PD, particularly for motor symptoms. Dopamine-resis- 
tant symptoms, however, such as freezing of gait, cognitive deficits, depression, dementia, and hallucinations, have become increasingly recognized as prevalent and as contributing disproportionately to morbidity. ${ }^{4}$ In addition, long-term treatment with dopaminergic medications may result in problematic motor fluctuations. Although DBS procedures in PD can treat medication-induced motor fluctuations in selected patients, there has been increasing recognition of cognitive and mood side effects of DBS, in addition to risks attendant with invasive surgical options. ${ }^{5}$ In dystonia, abnormal movements are treated by combinations of rehabilitation therapy, medications, botulinum toxin and, occasionally, DBS-all of which have significant rates of treatment failure. ${ }^{6}$

Within this context, noninvasive neuromodulation methods such as repetitive transcranial magnetic stimulation (rTMS) and transcranial direct current stimulation (tDCS) have the potential to fulfill adjunctive treatment roles by a rational and selective modulation of symptoms and their underlying neuropathophysiology on an individual basis. ${ }^{7}$ Because rTMS and tDCS are applied noninvasively over the scalp, these neuromodulatory techniques avoid both the complications associated with DBS surgery and the side effects of systemic medications.

Repetitive TMS or tDCS can, theoretically, be applied over selected cortical regions to modulate the particular cortical-subcortical network that is linked with a given subset of symptoms. In contrast, DBS, particularly in the subthalamic nucleus, stimulates small subcortical regions where multiple cortical-subcortical loops converge, which can result in unintended effects across multiple symptom domains. Furthermore, rTMS and tDCS can modulate or shape cortical excitability, a phenomenon that appears to underlie adaptive and maladaptive plasticity, which may be particularly relevant to dystonia (because, in dystonia, maladaptive plasticity is considered to play a prominent pathophysiologic role). ${ }^{8}$

In this review, we discuss the rationale and mechanisms for these noninvasive neuromodulation methods and summarize recent trials examining the clinical efficacy of rTMS and tDCS for PD and dystonia as exemplar movement disorders.

\section{OVERVIEW OF RTMS AND TDCS}

Repetitive transcranial magnetic stimulation (rTMS) refers to application of trains of repeated magnetic pulses delivered to the scalp. Passing a brief time-varying current through an insulated coil held parallel to the scalp surface generates a magnetic field perpendicular to the coil. This magnetic field, in turn, induces a weak eddy current within the underlying cerebral cortex. Whereas circular TMS coils induce a relatively nonfocal circular band of stimulation in the brain, focal figure- 8 coils can target stimulation with a functional spatial resolution of $0.5 \mathrm{~cm}$ to $1 \mathrm{~cm}^{9}$

Transcranial direct current stimulation (tDCS) refers to application of a constant direct current through a pair of surface electrodes affixed to the scalp. The low-intensity current (1-2 mA) flows from cathode to anode. Although the scalp possesses high impedance, sufficient intracranial current flows to produce changes in membrane resting thresholds within the cortex beneath each electrode. This results in an increase in activity under the anode and a decrease in activity beneath the cathode.

Contemporary interest in studying rTMS and tDCS as potential treatments for patient groups has been driven in part by observations that both methods can produce measurable effects that transiently outlast the duration of stimulation by at least $10 \mathrm{~min}$ to $90 \mathrm{~min} .{ }^{10-12}$ These effects are considered markers of lasting neuromodulatory effects. Because TMS discharges can perturb ongoing location- and task-specific cortical function and induce twitches of contralateral muscles (over motor cortex), application of rTMS is also considered a neurostimulatory method. In contrast, tDCS produces only a slight tingle as the current is turned on, but has little other discernible effect during application and is considered a predominantly neuromodulatory method.

Development of clinically relevant applications for these neuromodulatory methods depends on reliably inducing lasting effects, understanding their mechanisms, and determining causal clinical correlations in patient groups. Lasting neuromodulatory effects of rTMS or tDCS depend on both extrinsic and intrinsic factors as well as the outcome measures used. ${ }^{13}$ Extrinsic factors include intensity and frequency of rTMS, the number of pulses per session, the number of rTMS sessions, the interval between consecutive sessions, the targeted cortical region, the orientation of the coil, and the coil design. Intrinsic factors include the disease state being treated, the functional state of the brain during treatment, and interindividual variability.

Studies of rTMS and tDCS to date have been mostly small studies that necessarily tested only a subset of these intrinsic and extrinsic factors. Examples of outcomes used in rTMS and tDCS studies include measures of local cortical excitability, neuroimaging measures of function, and clinical outcomes. Although testing for clinical outcomes represents the ideal outcome measure for neuromodulation studies, the other outcome measures provide valuable information about mechanisms for rTMS or tDCS and provide quantitative measures with which to test effects of different intrinsic and extrinsic factors.

\section{Extrinsic factors}

Physiologic effects of rTMS depend on a large number of factors: coil geometry, stimulation site, intensity, fre- 
quency, duration of stimulation, and number of stimulation sessions. Circular TMS coils induce cortical currents that span at least the diameter of the coil; they are therefore less specific than more focal figure- 8 coils. The figure- 8 coils also provide the ability to target specific cortical regions.

Cortical excitability, defined as the responsiveness of the brain to stimulation, can be modulated systematically by rTMS and tDCS. Different rTMS frequencies produce bidirectional changes in healthy subjects, with low frequencies $(\leq 1 \mathrm{~Hz})$ suppressing cortical excitability and high frequencies $(>5 \mathrm{~Hz})$ facilitating it. ${ }^{14,15}$ These excitability changes are transient, lasting $10 \mathrm{~min}$ to $30 \mathrm{~min}$, with effects of longer duration generally linked to a higher number of pulses and higher intensities. ${ }^{11,16,17}$ Depending on the location of the cathode and anode, tDCS also produces differential lasting effects on cortical excitability. ${ }^{12}$ Anodal stimulation increases cortical excitability and cathodal stimulation decreases it. ${ }^{18-20}$ Furthermore, lasting effects of tDCS on cortical excitability tend to be greater with higher current intensities for longer durations. ${ }^{19}$ Converging evidence from pharmacologic and neurophysiologic studies supports the existence of modulation of synaptic strength in local cortical inhibitory and excitatory circuitry, similar to mechanisms of long-term potentiation and long-term depression, as putative mechanisms for these bidirectional frequency effects of rTMS and tDCS. ${ }^{15,21,22}$

To be clinically useful, rTMS and tDCS must induce changes that last longer than a few minutes or hours. Achieving this goal could require repeated sessions of rTMS or tDCS, similar to the model used for electroconvulsive therapy for depression. Two daily sessions of rTMS over the dorsal premotor cortex (PMd) in neurologically normal subjects can show a cumulative facilitation of primary motor cortex (M1) excitability on the second day. ${ }^{23}$ Cortical systems of neurologically affected patients have adapted to dysfunctional circuits, and this adaptation may render them more sensitive to effects of TMS or tDCS than in normal subjects, resulting in greater or longer-lasting responses. ${ }^{24,25}$ In support of this possibility, sustained changes in excitability were seen 1 week after rTMS over the PMd in PD patients, but no such changes were seen in a control group. ${ }^{25}$ Sustained cumulative clinical effects across repeated sessions have been reported, ${ }^{26-28}$ but the mechanisms of this effect require further investigation.

\section{Intrinsic factors}

Effects of rTMS are modulated by intrinsic factors that reflect interindividual differences. High-frequency versus low-frequency rTMS produces reliable bidirectional modulation of excitability as a group, but individuals show substantial variability in their response to rTMS, with some subjects showing facilitation of cortical excit- ability after 1-Hz rTMS and others showing excitability suppression after $10-\mathrm{Hz}$ rTMS. ${ }^{29}$ Recent studies have suggested a role for genetic polymorphisms in this interindividual variability in responses to rTMS. ${ }^{30}$

Although some intrinsic factors cannot be altered, others can be manipulated. Among PD patients, effects of rTMS differ depending on whether the patients are in a medication ON or OFF state. ${ }^{31,32}$ Similarly, among dystonia patients, excitability may differ depending on the context of a voluntary action or on the degree to which botulinum toxin treatment has also influenced cortical excitability. ${ }^{33}$ Principles of activity- and practice-dependent plasticity also suggest that combinations of rehabilitation therapies with rTMS or tDCS might have promise in facilitating beneficial neuromodulation, ${ }^{34}$ although few studies have yet been conducted to test this possibility.

\section{Outcome measures}

Cortical excitability outcomes. The most common outcomes used to quantify neuromodulation effects after rTMS and tDCS are those of cortical excitability. Studies investigating the effects of different extrinsic rTMS factors (frequency, duration, and intensity) generally report their results in terms of modulation of cortical excitability. Because cortical excitability is often altered in patients with PD or dystonia, excitability not only can be used a marker for the disorder of interest, but also can be used as an objective measure for testing extrinsic and intrinsic factors for combinations that would help restore abnormal excitability.

Various measures of excitability, such as motor thresholds, motor-evoked potentials (MEP), cortical silent period durations, and paired-pulse intracortical inhibition and facilitation, are defined based on different paradigms of single and paired-pulse TMS over the M1 while measuring responses in a target muscle using surface electromyography. Each cortical excitability measure tests different aspects of excitability. ${ }^{35}$ For example, motor threshold has been related to resting membrane excitability, ${ }^{36}$ duration of cortical silent period has been related to inhibition from $\mathrm{GABA}_{\mathrm{B}}$ receptors, ${ }^{37}$ and intracortical inhibition has been related to inhibition from $\mathrm{GABA}_{\mathrm{A}}$ receptors. ${ }^{38}$ Effects of rTMS and tDCS can thus be related to differential effects on various mechanistic influences on cortical excitability.

Neuroimaging outcomes. Effects of rTMS and tDCS on sites functionally connected to, but distant from, the site of stimulation can be assessed using a variety of neuroimaging outcome measures. ${ }^{39,40}$ Functional imaging with magnetic resonance imaging (fMRI) and with positron emission tomography (PET) has revealed abnormalities of cortical activation or blood flow (rCBF) within cortical and subcortical regions in movement disorder patients, suggesting that adaptive (or maladaptive) changes in cortical activity occur in these pa- 
tients in response to the particular disease state. ${ }^{41}$ Studies with neuroimaging outcomes showing that rTMS or tDCS can restore normal patterns of brain activity can provide further evidence as to which factors may be most relevant for clinical application of these neuromodulatory methods.

Measurements with $\left[{ }^{15} \mathrm{O}\right] \mathrm{H}_{2} \mathrm{O}$ PET indicated that $10-\mathrm{Hz}$ rTMS directed over the left middle prefrontal gyrus induced rapid rCBF changes not only under the stimulation site, but also in the functionally connected anterior cingulate gyrus. ${ }^{39}$ Similarly, after subthreshold 5-Hz rTMS over the M1, glucose metabolism assessed using with fluorodeoxyglucose PET was increased at the stimulation site and in both distant contralateral M1 and supplementary motor area (SMA). ${ }^{42}$ These distant effects on a task-specific network can be frequency dependent. In an $\left[{ }^{15} \mathrm{O}\right] \mathrm{H}_{2} \mathrm{O}$ PET study, 1-Hz rTMS induced a reduction but $5-\mathrm{Hz}$ rTMS induced a facilitation of connectivity between a network of several task-related motor regions. ${ }^{43}$

In contrast to neuroimaging of regional brain activation or $\mathrm{rCBF}$, both radioligand PET or single-photon emission computed tomography (SPECT) can image neurotransmitter changes within brain regions distant from the stimulation site and so provide additional insight into mechanisms of neuromodulation. Of particular interest for parkinsonian disorders, $10-\mathrm{Hz}$ rTMS over frontal cortex can induce focal dopamine release in subcortical basal ganglia structures, a finding that points to another potential mechanism for beneficial effects of rTMS in PD patients. Consistent with the functional somatotopy of striatocortical loops, rTMS of dorsolateral prefrontal cortex (DLPFC) induced dopamine release in the caudate ${ }^{44}$ and M1 induced dopamine release in the ventrolateral putamen. ${ }^{45}$

Clinical outcomes. For adjunctive management of movement disorder patients, the goal with rTMS and tDCS is to provide symptomatic benefit for patients with a minimum of adverse effects. Achieving these goals requires clinically relevant outcomes that are specific to each disorder. These are discussed here, in separate sections, for both PD and dystonia.

In contrast to subcortical continuous stimulation in DBS, two particular advantages of the noninvasive cortical neuromodulation approach are the temporal and spatial specificity of each stimulation session. Temporal specificity refers to the ability to deliver each rTMS or tDCS session during particular individual contexts, and so to provide control of some intrinsic factors. For example, future studies may help to clarify the differential effects of neuromodulation during ON or OFF medication state in PD patients, during botulinum toxin therapy in dystonia patients, or during rehabilitation concurrently with tDCS, thereby allowing a determination of the optimal time to apply rTMS or tDCS. The spatial specificity of neuromodulation arises from the ability to stimulate cortical regions within brain networks that are relatively specific for separate groups of symptoms. Examples in PD patients include the targeting of dyskinesia symptoms by rTMS over the SMA ${ }^{46}$ or distinguishing mood from motor effects by rTMS over cortical regions involved with each particular domain. ${ }^{13}$

Finally, study designs must account for placebo effects for all outcome measures, and for clinical rating scales in particular. Because placebo effects are prominent in studies of investigational devices, and especially in PD patients, clinical studies of rTMS and tDCS require explicit attention to sham neuromodulatory conditions. ${ }^{47,48}$ The auditory click and scalp sensations of TMS make a true sham condition a unique challenge. ${ }^{49}$ Because the low current in tDCS cannot be felt after being turned on, sham tDCS conditions are indistinguishable from real tDCS conditions. ${ }^{50}$

\section{Safety}

Both rTMS and tDCS are generally safe, noninvasive procedures with minimal adverse effects. Of most significant concern has been the possibility of inadvertent seizures due to rTMS. Because rare seizures have been associated with prolonged trains of high-frequency rTMS at high intensities, rTMS stimulation parameters in human subjects are limited by safety guidelines to minimize this risk. ${ }^{51,52}$ Since publication of these guidelines, experience with rTMS (including high frequencies, different patient populations, and use over nonmotor regions) has largely confirmed the safety of rTMS under current guidelines. ${ }^{53}$ To date, the literature contains reports on several hundred patients with movement disorders who have been studied with rTMS, with no reports of accidental seizures. Among movement disorder patients, no study has shown worsening of clinical rating scores, and only one study (over the SMA) reported a subclinical worsening spiral drawing. ${ }^{54}$ tDCS is well tolerated, with little recognized risk for seizures. Concerns focus on limiting current flow to less than $2 \mathrm{~mA}$ and ensuring adequate electrode size to minimize current density on the scalp.

Even given this safety record, caution is required with neuromodulation. Careful monitoring for adverse effects remains warranted, particularly for protocols developed using novel stimulation methods (e.g., theta burst), ${ }^{55}$ multiple-session rTMS or tDCS, or context-related stimulations that aim to have longer-lasting or greater modulation of plasticity.

\section{PARKINSON'S DISEASE}

Parkinson's disease is characterized by the involvement of multiple neuroanatomical pathways, ${ }^{56}$ with some of the best-recognized clinical features resulting 
from degeneration of dopaminergic neurons in the substantia nigra resulting in functional dopamine depletion in the striatum. The degeneration of dopaminergic nigrostriatal pathways results in deafferentation of functional targets in the cortex, which likely contributes to the pathophysiology of motor and nonmotor disturbances in patients with PD. Cortical consequences of this deafferentation include alterations in cortical excitability ${ }^{57}$ and in task-specific network activity. ${ }^{58}$ Factors investigated for rTMS and tDCS neuromodulation in PD thus include those that induce dopamine release and that can normalize abnormal cortical excitability or network activity.

\section{Dopamine release hypothesis}

The finding that cortical rTMS can induce release of subcortical dopamine ${ }^{44,45}$ has raised interest in this phenomenon as a potential mechanism for clinical benefits from rTMS in PD. In PD patients, Strafella et al. ${ }^{59}$ showed that $10-\mathrm{Hz}$ rTMS over the M1 can release dopamine in mild hemiparkinsonian PD patients, and that the release is greater in the more affected hemisphere. This study was not designed to examine clinical benefit, nor did it include control subjects. A subsequent study demonstrated that sham rTMS in moderate PD patients also showed subcortical dopamine release, ${ }^{60}$ leading to uncertainties as to the significance of dopamine release by rTMS.

Two multisession rTMS studies have also addressed the dopamine release hypothesis. A significant reduction of CSF homovanillic acid (HVA) was reported in PD patients who had received weekly sessions of $0.2-\mathrm{Hz}$ rTMS over 3 to 4 months. ${ }^{61}$ Because HVA is a dopamine metabolite, this effect was interpreted as inhibiting the dopamine system (despite the observation that PD symptoms improved), a finding at odds with a dopamine release hypothesis. Given no parallel control group, however, and the lack of correlation between CSF HVA levels and PD severity, ${ }^{62}$ these CSF results are of uncertain clinical significance. Khedr et al. ${ }^{63}$ recently reported an increase in serum dopamine levels immediately after 6 days of daily $25-\mathrm{Hz}$ rTMS sessions over the M1, and the increase correlated with motor UPDRS scores. The degree to which serum dopamine levels correlate with striatal dopaminergic function is unclear, however, and this study was without a control group. Better-controlled studies are needed to investigate the validity and clinical significance of the rTMS dopamine release hypothesis.

\section{Normalization of network activation}

From a variety of neuroimaging studies, common patterns of cortical activation in PD patients have emerged. In general, decreased activity has been reported around the SMA (and often including pre-SMA) and DLPFC with increased activity in parietal and lateral premotor areas in PD patients. ${ }^{64,65}$ Although the hypoactive brain areas are usually interpreted as a primary dysfunction associated with parkinsonian symptoms, the hyperactivity has been interpreted as a neural correlate of adaptive plasticity within the motor system, compensation for the defective cortical-basal ganglia-thalamocortical circuitry. ${ }^{65}$ Overactivity of premotor-parietal circuits in PD has been thought to represent a compensatory mechanism for deficient activation of impaired striato-mesial-frontal projections. $^{66}$ Symptomatic therapy with either levodopa $^{64}$ or subthalamic nucleus (STN) stimulation ${ }^{67}$ can partially reverse these abnormalities.

These studies suggest a variety of cortical targets for neuromodulation. For example, one might speculate that facilitatory rTMS could be used to enhance activity (and excitability) in hypoactive cortical areas and thereby improve clinical function. Furthermore, neuromodulation can focus on certain cortical nodes within functionally segregated striatocortical circuits, to further target selected symptoms. For example, a motor-putamen loop might be targeted by rTMS over the M1 for modulation of motor symptoms but the prefrontal-caudate loop might be targeted by rTMS over the DLPFC for modulation of depression symptoms.

\section{Normalization of excitability}

Studies of cortical excitability determinants in PD indicate an elevated resting excitability with activity-associated impairment of facilitation. The elevated resting excitability has been reported with larger MEPs, shorter cortical silent period durations, and lower short-latency intracortical inhibition in PD patients than in normal subjects. $^{68,69}$ During movement preparation, normal MEP facilitation during premovement periods is reduced in PD patients. ${ }^{69,70}$ The slow recruitment of M1 excitability prior to voluntary movement often is interpreted as a primary correlate for bradykinesia, whereas elevated resting excitability represents a compensatory response that makes it easier to recruit activity from a resting state. ${ }^{66}$ However, the cortical disinhibition during active contraction suggested by shorter cortical silent period in PD does not follow this model and may also be associated with the compensatory response to bradykinesia. ${ }^{71}$ As with network activations in fMRI studies, these excitability abnormalities also partially normalize with dopaminergic $^{72}$ or DBS therapy. ${ }^{73}$

Clinical correlations to excitability changes in PD are relatively sparse and probably depend on individual symptoms and degree of cortical compensation. Enhanced MEP size at rest has been linked to rigidity in $\mathrm{PD},{ }^{68}$ subliminal motor thresholds to bradykinesia, ${ }^{74}$ and cortical silent period durations to UPDRS scores on the more affected side in early PD, ${ }^{71}$ but many studies report no such correlations. Even so, assessment of normalization of selected excitability measures remains potentially useful, though not yet validated, as a marker for clinical improvement after rTMS. 


\section{Studies of rTMS in Parkinson's disease with clinical outcomes}

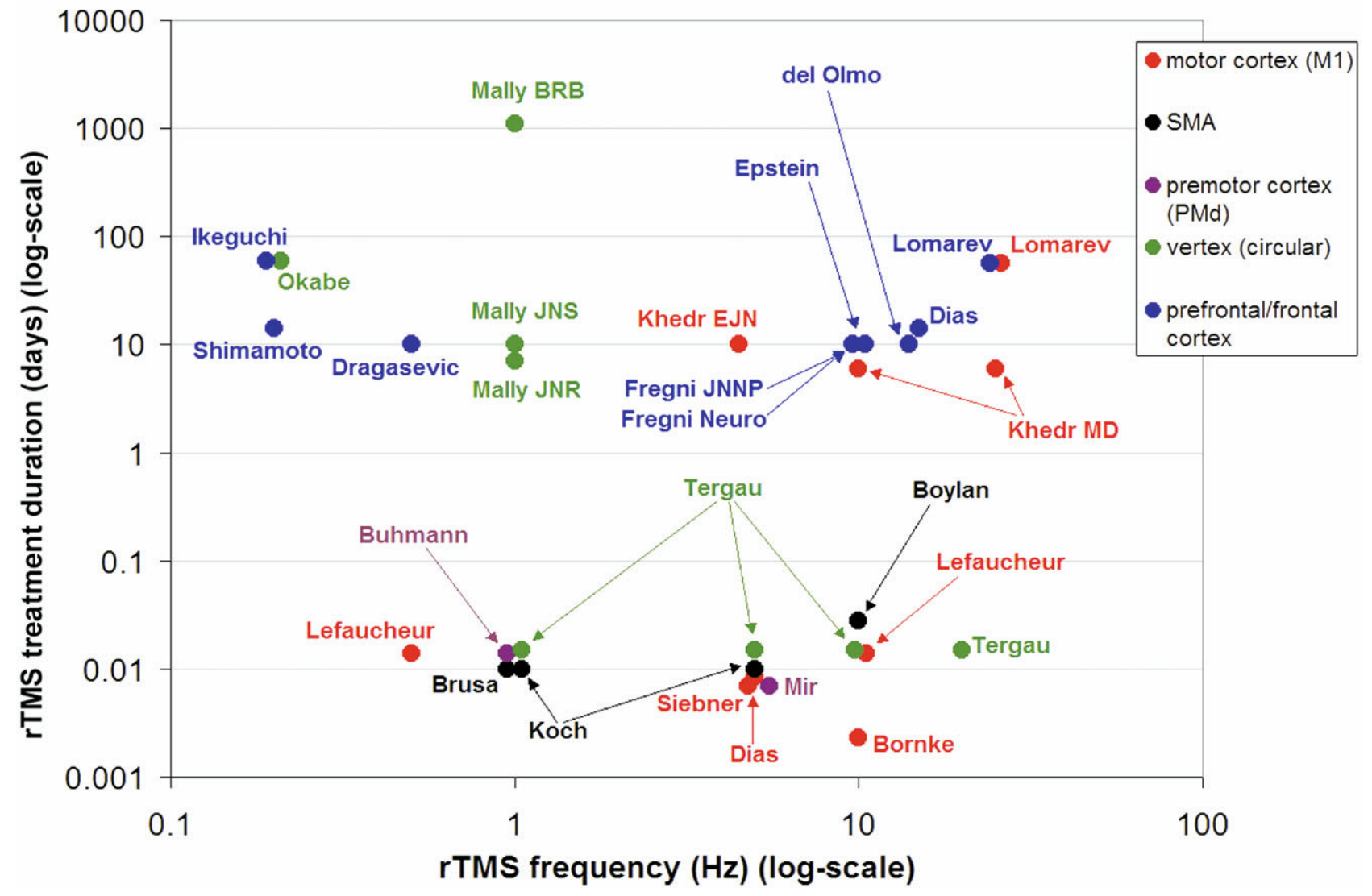

FIG. 1. Variation in extrinsic transcranial magnetic stimulation (TMS) factors in studies of repetitive TMS (rTMS) in Parkinson's disease. Log-log plot of three TMS factors: frequency (horizontal axis), total duration of treatment (vertical axis), and stimulation site (color). References: Börnke ${ }^{92}$; Boylan ${ }^{54}$; Brusa ${ }^{80}$; Buhmann ${ }^{25}$; del Olmo ${ }^{96}$; Dias ${ }^{97}$; Dragaševic ${ }^{76}$; Epstein ${ }^{79}$; Fregni JNNP ${ }^{78}$; Fregni Neuro ${ }^{28}$; Ikeguchi ${ }^{44}$; Khedr EJN ${ }^{27}$; Khedr MD ${ }^{93}$; Koch ${ }^{46}$; Lefaucheur ${ }^{11}$; Lomarev ${ }^{26}$; Mally JNS ${ }^{135}$; Mally JNR ${ }^{136}$; Mir ${ }^{83}$; Okabe ${ }^{82}$; Shimamoto ${ }^{61}$; Siebner ${ }^{89}$; Tergau ${ }^{81}$.

\section{Clinical outcomes in PD after neuromodulation}

Among studies that have applied rTMS in PD patients with clinical outcomes measured, extrinsic repetitive rTMS factors vary widely. This variation is exemplified in Figure 1, which plots the distribution of published rTMS studies with clinical outcomes across three extrinsic factors: site of stimulation, frequencies tested, and treatment durations. Although treatment durations vary among studies, both single-session and multisession studies have suggested benefit across a range of cortical sites, with most multisession studies following a model of daily sessions over 7 to 14 days.

Study designs, patient populations, duration of follow-up, and outcome measures are highly variable. For clinical outcome measures, all but one study ${ }^{75}$ used the Unified Parkinson's Disease Rating Scale (UPDRS) as clinical outcome measures. For particular symptoms, additional rating scales for depression ${ }^{76-79}$ or dyskinesias ${ }^{46,80}$ were used. Many early studies were not placebo- or sham-controlled. Despite these differences, all but four studies ${ }^{54,81-83}$ reported some benefit in clinical ratings of PD symptoms. Although this may be due in part to publication bias, a recent metaanalysis reveals an overall beneficial effect of rTMS, including a subanalysis restricted to sham-controlled studies. ${ }^{84}$

A circular coil centered over the vertex stimulates a wide variety of cortical areas and does not lend well to interpretation of a mechanism or rationale for treatment. These studies tend to showed poor reproducibility with no benefit reported in controlled studies across low and high frequencies. ${ }^{81,82}$ In most later studies, figure- 8 coils were used to provide greater selectivity for spatial location and from which to interpret potential mechanisms. Although the SMA and PMd have been explored in few studies, the most common sites studied are M1 and DLPFC, which correspond to cortical targets of motor and prefrontal basal ganglia-thalamic loops, respectively.

Motor cortex stimulation. The M1 is a key cortical target for the motor cortical-subcortical loop. The standard basal ganglia circuit model implicates impaired basal ganglia-thalamo-cortical drive as a cause for motor PD symptoms ${ }^{58}$ and so the M1 is a common site for cortical neuromodulation to facilitate deficient thalamo- 
TABLE 1. Repetitive Transcranial Magnetic Stimulation Studies in PD Patients Over Primary Motor Cortex with Clinical Outcome Measures

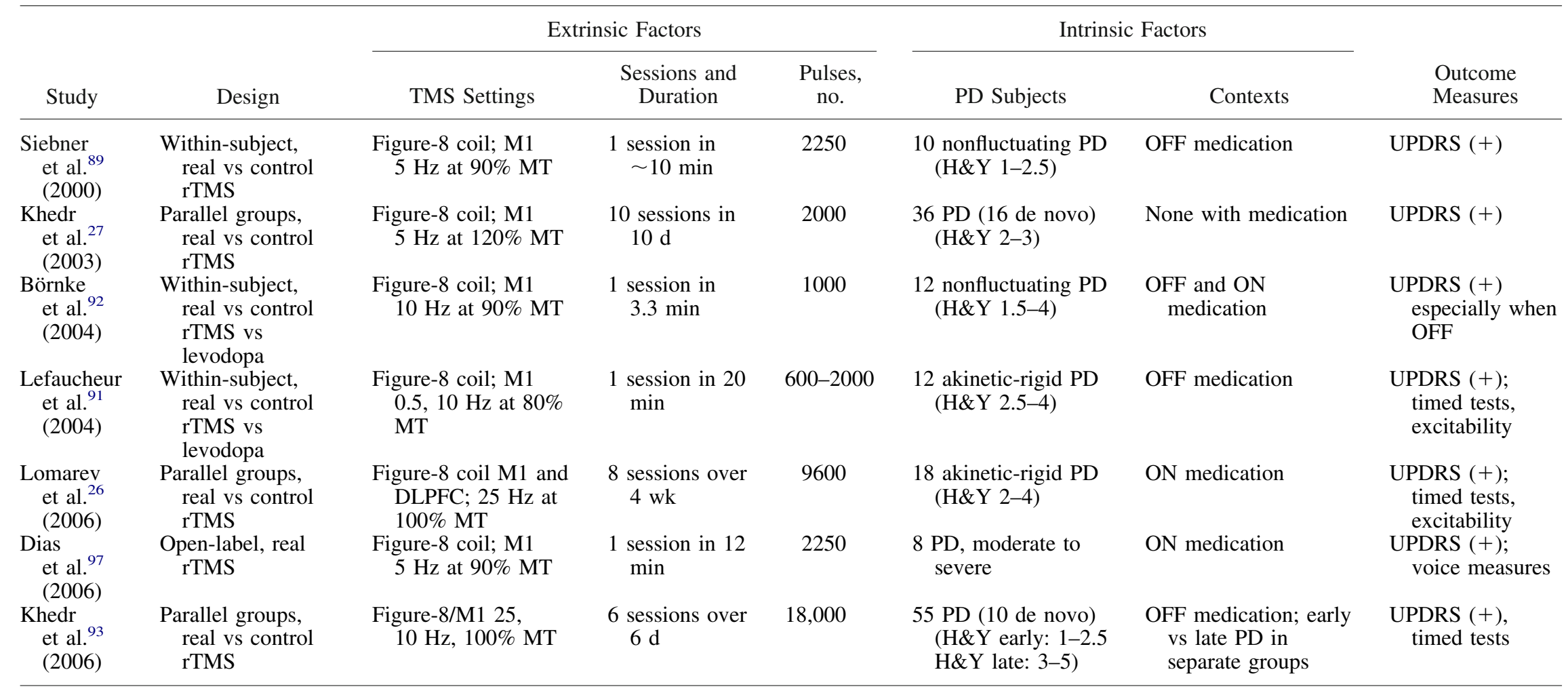

DLPFC $=$ dorsolateral prefrontal cortex H\&Y $=$ Hoehn and Yahr rating scale, $\mathrm{M} 1=$ primary motor cortex, MT $=$ motor threshold; PD $=$ Parkinson's disease; rTMS = repetitive transcranial magnetic stimulation; TMS = transcranial magnetic stimulation; UPDRS = Unified Parkinson's Disease Rating Scale; $(+)=$ significant improvement in UPDRS ratings. 
cortical drive. Repetitive TMS studies over motor cortex are summarized in Table 1.

The first encouraging report of rTMS in PD patients used low-intensity, subthreshold 5-Hz rTMS over the M1 and found improvement in simple and choice reaction time and pegboard task performance ${ }^{85}$; however, these results were subsequently not replicated in a less severely affected PD group. ${ }^{86}$ Interpretation of these studies was limited by the fact that task function was examined during rTMS. Because TMS stimulation over the M1 might well be predicted to impair ongoing fine motor control, the lasting effects after rTMS trains could more theoretically lead to motor benefits. ${ }^{87}$ This offline use of rTMS has become the predominant model for investigating possible benefits of rTMS in patients and constitutes the focus here in this review.

In a series of single-session studies, Siebner et al. ${ }^{88}$ illustrated lasting effects after high-frequency rTMS over the motor cortex on several outcome measures that suggested benefit to motor symptoms in PD. Repetitive TMS at $5 \mathrm{~Hz}$ over the hand region of the M1 showed normalization of cortical silent periods ${ }^{88}$ with improvement in clinical measures of contralateral bradykinesia ${ }^{89}$ and measures of an aiming movement without loss of accuracy. ${ }^{90}$ Lefaucheur et al. ${ }^{91}$ confirmed benefits of M1 rTMS at both low $(0.5 \mathrm{~Hz})$ and high $(10 \mathrm{~Hz})$ frequencies. Although 10-Hz rTMS reduced contralateral bradykinesia, at $0.5 \mathrm{~Hz}$ the rTMS reduced bilateral rigidity and improved gait speed. Both frequencies normalized silent periods, but whereas $0.5-\mathrm{Hz}$ rTMS normalized intracortical inhibition, 10-Hz rTMS enhanced intracortical facilitation. Thus, theories of mechanisms for benefits of M1 rTMS must account for modulation of both excitatory and inhibitory circuits. Börnke et al. ${ }^{92}$ showed that single-sessions of $10-\mathrm{Hz}$ rTMS could improve measures comparably to that of levodopa. Taken together, these studies provide preliminary evidence that a single session of either low- or high-frequency rTMS over the M1 might improve motor symptoms in PD, relative to sham stimulation, with more studies using high frequencies to enhance abnormal impaired thalamocortical drive in PD.

All of the published multisession studies over the M1 have been conducted with high-frequency rTMS and have included a sham-TMS control. Khedr et al. ${ }^{27}$ applied suprathreshold 5-Hz rTMS over arm and leg areas of the M1 daily for 10 days in unmedicated PD patients. Results showed a cumulative improvement in the rTMS treatment group, compared with a sham-rTMS group, in UPDRS motor subscale scores and in walking speed, improvement that persisted 1 month after rTMS. In a follow-up study, early- and late-stage PD patients were studied with both $10 \mathrm{~Hz}$ and $25 \mathrm{~Hz}$ daily rTMS over 6 days. ${ }^{93}$ Results showed cumulative improvement in UPDRS, gait, and tapping speed in groups receiving rTMS, compared with control-site rTMS over the occipital cortex. The greatest benefits were seen with $25-\mathrm{Hz}$ rTMS in the early PD patients, and benefits persisted for up to 1 month after treatment. Notably, additional open-label rTMS treatments (daily sessions for 3 days) at monthly intervals appeared to counteract transient wearing-off of benefits from previous rTMS treatments.

Prefrontal cortex stimulation. The DLPFC is a key cortical target for the prefrontal cortical-subcortical loop, a circuit that is involved with attention, working memory, and mood regulation. In addition, a majority of studies applying rTMS as treatment for depression have used high frequencies to the left DLPFC with focal figure- 8 coils. To date, all published DLPFC rTMS studies have been multisession studies, and several have focused on depressed PD patients. Repetitive TMS studies over prefrontal cortex are summarized in Table 2 .

A few early DLPFC studies also used circular coils centered over prefrontal regions ${ }^{61,76,94,95}$ Although these studies showed clinical benefit, they used nonfocal coils with very low frequencies $(0.2 \mathrm{~Hz})$ that, in normal control subjects, do not produce long-lasting excitability changes. ${ }^{15}$

In an open-label study of depressed PD patients, 10 daily sessions of 10-Hz rTMS over the left DLPFC suggested benefits on both depression scales and UPDRS motor scores when off medication. ${ }^{79}$ In a sham-TMS and active medication treatment control study of depressed PD patients, Fregni et al. ${ }^{78}$ showed that a 10 -day course of $15-\mathrm{Hz}$ rTMS over the left DLPFC (plus placebo medication) had an equivalent efficacy on depression rating scales as fluoxetine antidepressant (plus sham rTMS), an effect that persisted for 8 weeks.

The effects of rTMS on DLPFC may be specific for depression, rather than for motor symptoms. A recent study reported that 10 days of $10-\mathrm{Hz}$ rTMS over the DLPFC in nondepressed PD patients did not have a significant effect on motor measures of finger tapping, reaching, and gait beyond that of motor practice. ${ }^{96} \mathrm{Sim}$ ilarly, 10 sessions of $15-\mathrm{Hz}$ rTMS over the DLPFC showed no effect on quantitative measures of speech volume and intensity, compared with sham rTMS, but open-label single sessions of 5-Hz rTMS over the mouth area of the M1 showed motor speech improvement in voice intensity and fundamental frequency. ${ }^{97}$

Two imaging studies have investigated the mechanisms of rTMS DLPFC modulation in PD on the cortical activity. Fregni et al. ${ }^{28}$ contrasted rTMS with fluoxetine treatment while investigating the pathophysiological basis for outcomes using SPECT measures of rCBF. PD patients with depression showed reduced baseline $\mathrm{rCBF}$ in areas involved in mood regulation, including left prefrontal cortex and posterior cingulate. Both rTMS and fluoxetine led to equivalent improvement in depression, but rTMS differentially increased $\mathrm{rCBF}$ in bilateral prefrontal cortex, whereas the fluoxetine group showed increased rCBF in the occipital lobe. An fMRI study, also addressing the neural correlates of depression treatment 
TABLE 2. Repetitive TMS in PD Patients Over Prefrontal Cortex with Clinical Outcome Measures

\begin{tabular}{|c|c|c|c|c|c|c|c|}
\hline \multirow[b]{2}{*}{ Study } & \multirow[b]{2}{*}{ Design } & \multicolumn{3}{|c|}{ Extrinsic Factors } & \multicolumn{2}{|c|}{ Intrinsic Factors } & \multirow[b]{2}{*}{ Outcome Measures } \\
\hline & & TMS Settings & $\begin{array}{l}\text { Sessions and } \\
\text { Duration }\end{array}$ & $\begin{array}{c}\text { Pulses, } \\
\text { no. }\end{array}$ & PD Subjects & Contexts & \\
\hline $\begin{array}{l}\text { Shimamoto } \\
\text { et al. }{ }^{6} \\
(2001)\end{array}$ & $\begin{array}{l}\text { Parallel groups, } \\
\text { real vs control } \\
\text { rTMS }\end{array}$ & $\begin{array}{l}\text { Circular coil; PFC } \\
0.2 \mathrm{~Hz} \text { at } 78 \% \\
\text { MSO }\end{array}$ & $\begin{array}{l}\sim 8 \text { sessions in } \\
2 \text { mo }\end{array}$ & $\sim 480$ & 18 PD (H\&Y 1-4) & - & $\begin{array}{l}\text { UPDRS }(+), \text { CSF } \\
\text { HVA }\end{array}$ \\
\hline $\begin{array}{l}\text { Dragaševic } \\
\text { et al. } \\
\text { (2002) }\end{array}$ & $\begin{array}{l}\text { Open-label, real } \\
\text { rTMS }\end{array}$ & $\begin{array}{l}\text { Circular coil; PFC } \\
0.5 \mathrm{~Hz} \text { at } 110 \% \\
\text { MT }\end{array}$ & $\begin{array}{l}10 \text { sessions in } \\
10 \mathrm{~d}\end{array}$ & 2000 & $\begin{array}{l}10 \text { depressed PD } \\
(\text { H\&Y 1-3) }\end{array}$ & $\begin{array}{l}\text { Depressed PD } \\
\text { patients }\end{array}$ & $\begin{array}{l}\text { UPDRS }(+), \\
\text { HDRS }(+), \\
\text { timed tapping }\end{array}$ \\
\hline $\begin{array}{l}\text { Ikeguchi } \\
\text { et al. }{ }^{94} \\
(2003)\end{array}$ & $\begin{array}{l}\text { Parallel groups, } \\
\text { real vs control } \\
\text { rTMS }\end{array}$ & $\begin{array}{l}\text { Circular coil; frontal } \\
0.2 \mathrm{~Hz} \text { at } 70 \% \\
\text { MSO }\end{array}$ & $\begin{array}{l}6 \text { sessions in } 2 \\
\text { wk }\end{array}$ & 360 & $\begin{array}{l}12 \text { nonfluctuating PD } \\
\text { (H\&Y 1-4) }\end{array}$ & - & $\begin{array}{l}\text { UPDRS }(+) \text {, timed } \\
\text { tasks, SPECT } \\
\text { rCBF }\end{array}$ \\
\hline $\begin{array}{l}\text { Fregni } \\
\text { et al. }{ }^{78} \\
\quad(2004)\end{array}$ & $\begin{array}{l}\text { Parallel groups, } \\
\text { real rTMS vs } \\
\text { SSRI }\end{array}$ & $\begin{array}{l}\text { Figure-8 coil; } \\
\text { DLPFC } 15 \mathrm{~Hz} \text { at } \\
110 \% \mathrm{MT}\end{array}$ & $\begin{array}{l}10 \text { sessions in } \\
10 \mathrm{~d}\end{array}$ & 30,000 & $\begin{array}{l}42 \text { PD with } \\
\text { depression (H\&Y } \\
1-4)\end{array}$ & $\begin{array}{l}\text { PD patients with } \\
\text { depression }\end{array}$ & $\begin{array}{l}\text { UPDRS }(+), \\
\text { HDRS }(+) \\
\text { equivalent to } \\
\text { SSRI }\end{array}$ \\
\hline $\begin{array}{l}\text { Lomarev } \\
\text { et al. } \\
(2006)\end{array}$ & $\begin{array}{l}\text { Parallel groups, } \\
\text { real vs control } \\
\text { rTMS }\end{array}$ & $\begin{array}{l}\text { Figure- } 8 \text { coil M1 and } \\
\text { DLPFC; } 25 \mathrm{~Hz} \text { at } \\
100 \% \mathrm{MT}\end{array}$ & $\begin{array}{l}8 \text { sessions over } \\
4 \mathrm{wk}\end{array}$ & 9600 & $\begin{array}{l}18 \text { akinetic-rigid PD } \\
(\text { H\&Y 2-4) }\end{array}$ & ON medication & $\begin{array}{r}\text { UPDRS }(+) \text {; timed } \\
\text { tests, excitability }\end{array}$ \\
\hline $\begin{array}{l}\text { Dias } \\
\quad \text { et al. } \\
\quad(2006)\end{array}$ & $\begin{array}{l}\text { Parallel groups, } \\
\text { real rTMS vs } \\
\text { SSRI }\end{array}$ & $\begin{array}{l}\text { Figure-8 coil; } \\
\text { DLPFC } 15 \mathrm{~Hz} \text { at } \\
110 \% \mathrm{MT}\end{array}$ & $\begin{array}{l}10 \text { sessions } \\
\text { over } 2 \mathrm{wk}\end{array}$ & 30,000 & $\begin{array}{l}22 \text { PD, moderate to } \\
\text { severe }\end{array}$ & ON medication & $\begin{array}{l}\text { UPDRS (0); voice } \\
\text { measures }\end{array}$ \\
\hline $\begin{array}{l}\text { Epstein } \\
\text { et al. } \\
(2007)\end{array}$ & $\begin{array}{l}\text { Open-label, real } \\
\text { rTMS }\end{array}$ & $\begin{array}{l}\text { Figure-8 coil; } \\
\text { DLPFC } 10 \mathrm{~Hz} \text { at } \\
110 \% \mathrm{MT}\end{array}$ & $\begin{array}{l}10 \text { sessions } \\
\text { over } 2 \mathrm{wk}\end{array}$ & 19,000 & $\begin{array}{l}14 \text { PD with } \\
\text { depression }\end{array}$ & $\begin{array}{l}\text { PD patients, with } \\
\text { moderate to } \\
\text { severe } \\
\text { depression }\end{array}$ & $\begin{array}{l}\text { UPDRS }(+) \text { when } \\
\text { OFF, HDRS }(+)\end{array}$ \\
\hline $\begin{array}{l}\text { del Olmo } \\
\text { et al. } \\
\text { (2007) }\end{array}$ & $\begin{array}{l}\text { Parallel groups, } \\
\text { real vs control } \\
\text { rTMS }\end{array}$ & $\begin{array}{c}\text { Figure-8/DLPFC } 10 \\
\mathrm{~Hz} \text { at } 90 \% \mathrm{MT}\end{array}$ & $\begin{array}{l}10 \text { sessions } \\
\text { over } 10 \mathrm{~d}\end{array}$ & 4500 & 13 PD (H\&Y 1-3) & ON medication & $\begin{array}{l}\text { UPDRS }(0), \text { timed } \\
\text { tasks }\end{array}$ \\
\hline
\end{tabular}

Included are studies with circular coils centered over prefrontal sites.

$\mathrm{CSF}=$ cerebrospinal fluid; DLPFC = dorsolateral prefrontal cortex; H\&Y = Hoehn and Yahr rating scale; HDRS = Hamilton Depression Rating Scale; HVA = homovanillic acid; M1 = primary motor cortex; MSO = maximum stimulator output; MT = motor threshold; PD = Parkinson's disease; PFC = prefrontal cortex; rCBF = relative cerebral blood flow; SSRI = selective serotonin reuptake inhibitor (antidepressant); UPDRS = Unified Parkinson's Disease Rating Scale; $(+)=$ significant improvement in either UPDRS or HDRS; $(0)=$ no significant change in clinical ratings. 
in PD with multiple sessions of 5-Hz rTMS over the left DLPFC versus fluoxetine, found that rTMS produced increased activation in the left DLPFC and anterior cingulate with decreased activation in the right DLPFC, right fusiform gyrus and cerebellum. Fluoxetine showed an increased activation in the right medial and lateral premotor regions, but no changes around either right or left DLPFC. ${ }^{98}$ Differences between these imaging findings likely reflect differences in rTMS factors and the emotional face observation paradigm used for activation in the fMRI study versus resting $\mathrm{rCBF}$ in the SPECT study. Both studies, however, support effects of rTMS over the DLPFC circuits, effects not seen in the fluoxetine groups, and suggest that the local normalization of hypoactivity of DLPFC in depressed PD patients may in part underlie rTMS associated improvements in mood.

Combined motor and prefrontal stimulation. In a placebo-controlled, multisession study, Lomarev et al. ${ }^{26}$ showed improvement in timed motor tasks and UPDRS scores over eight sessions over 4 weeks with $25-\mathrm{Hz}$ rTMS over the M1 and DLPFC. Improvement in upper extremity bradykinesia was correlated with increase in MEP size after each session of rTMS. However, because MEP size did not increase when compared before and after all eight sessions of rTMS, the mechanism for cumulative benefits of rTMS cannot be explained solely by a long-lasting facilitation of cortical excitability. Nevertheless, the cumulative clinical improvement in gait and upper extremity bradykinesia lasted at least 1 month after the rTMS course.

Although the use of several cortical targets simultaneously confounds the ability to determine the topographic effects of high-frequency rTMS over the DLPFC or M1, this protocol illustrates a potential use of rTMS to simultaneously modulate different striatocortical loops. Mood or cognitive outcome measures would therefore have been of interest in this protocol. Future combined studies could consider modulation of different striatocortical loops with individually tuned factors for each circuit or set of symptoms.

Supplementary motor area stimulation. Imaging data have for the most part supported underactivity of the SMA (and pre-SMA) as playing an important role in PD bradykinesia, ${ }^{64}$ although some task-related paradigms do show overactivation of the SMA. ${ }^{99}$ However, the location of the SMA within the interhemispheric fissure makes it a difficult noninvasive cortical target. Furthermore, the proximity of the anterior pre-SMA (related to prefrontal circuits) to the SMA proper (related to motor circuits) makes selective topographic targeting of rTMS more difficult.

In terms of targeting specific symptom sets in PD, several studies have investigated rTMS over the SMA for the modulation of dyskinesias in PD patients (Table 3 ). Dyskinesias are abnormal medication-induced involuntary movements that develop in many advanced PD

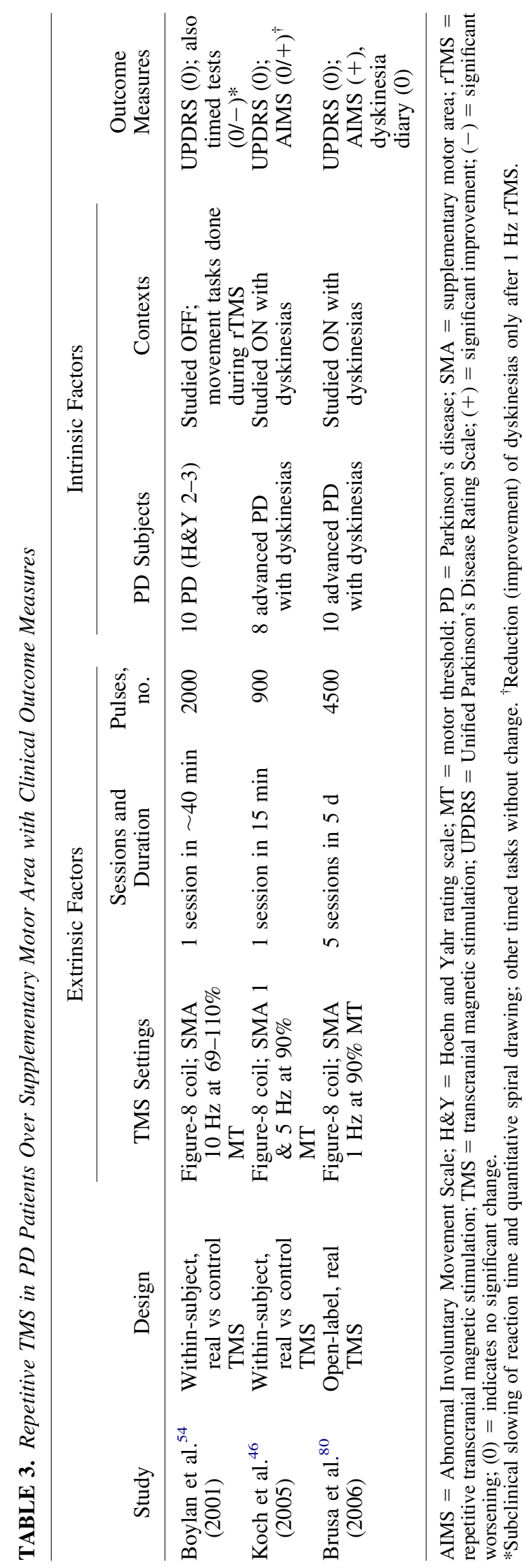


patients and that may limit the ability for medications to remain optimally effective. Functional neuroimaging has demonstrated overactivation of the SMA in patients with dyskinetic PD. ${ }^{100,101}$

Consistent with bidirectional frequency modulation of SMA activity, 1-Hz rTMS over the SMA was able to transiently reduce drug-induced dyskinesias, and $5-\mathrm{Hz}$ rTMS was associated with a nonsignificant increase of dyskinesias. ${ }^{46}$ However, the transient benefits of rTMS on dyskinesias did not appear to be enhanced when $1-\mathrm{Hz}$ rTMS was applied across daily sessions. ${ }^{80}$

In these SMA studies, no adverse effects or motor deterioration were observed in rTMS conditions. An early study, using $10-\mathrm{Hz}$ rTMS over the SMA in PD patients, showed a subclinical slowing of reaction time and impairment of spiral drawing, which may have been related to the high intensities and frequencies over an area of the brain with convergent connections to both prefrontal and motor circuits. ${ }^{54}$

Premotor cortex stimulation. Two studies have investigated effects of rTMS over the PMd as a cortical target, but neither study had clinical behavior as a primary outcome (Table 4). In a study in early-stage, untreated PD patients, 1-Hz rTMS over the PMd was applied and lasting effects on excitability were assessed with single-pulse TMS over the M1. ${ }^{25}$ Notably, effects on paired-pulse intracortical excitability after premotor rTMS persisted 1 week after rTMS, which was not seen in healthy control subjects. ${ }^{25}$ Nonspecific improvements in motor performance and UPDRS were attributed to training, a placebo effect, or both. In the other study, 5-Hz rTMS over the PMd was shown to modulate M1 excitability in normal subjects, but not in PD patients off medication. Dopaminergic medication restored the ability for 5-Hz rTMS over the PMd to facilitate M1 excitability in PD patients.

tDCS in Parkinson's disease. To date, there have been only two publications on tDCS and PD. In the 2006 study reported by Fregni et al., ${ }^{102}$ the motor effects of single-session tDCS of the M1 and DLPFC in PD patients were studied in the OFF state. This study showed that anodal tDCS of the M1 results in a significant motor function enhancement in PD, as indexed by simple reaction time and motor scores of UPDRS, compared with sham stimulation. These effects were specific for tDCS polarity and site of stimulation; cathodal stimulation of the M1 and anodal stimulation of the DLPFC induced small effects that were not significantly different from sham stimulation. In addition, tDCS effects were associated with a polarity-dependent effect on corticospinal motor excitability in PD patients: whereas anodal stimulation resulted in a robust increase of corticospinal excitability, cathodal stimulation slightly decreased it. We note that the increase in the M1 excitability after anodal tDCS was marginally correlated with motor function

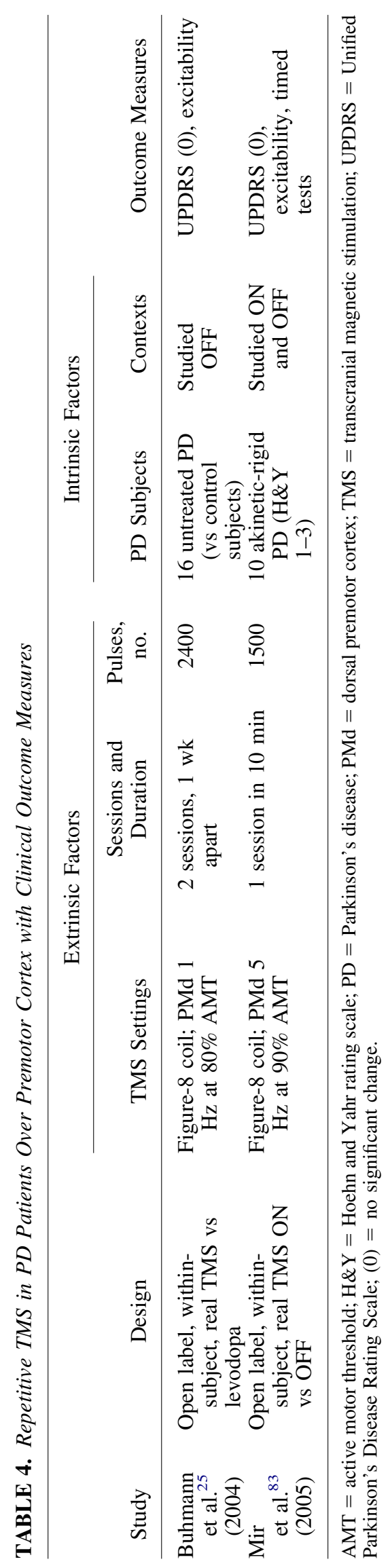

Neurotherapeutics, Vol. 5, No. 2, 2008 
improvement. This result might be seen as paradoxical, compared with rTMS studies, because a potential mechanism for rTMS effects is the normalization of enhanced resting cortical excitability. However, this tDCS study evaluated only one particular measure of corticospinal excitability (i.e., MEP amplitude and area), and it is possible that anodal tDCS might have modulated intracortical excitability in the same direction as rTMS, as shown in normal subjects. ${ }^{103}$

In another tDCS study by the same group, working memory was assessed in PD. ${ }^{104}$ There was a significant improvement in working memory, as indexed by task accuracy, after active anodal tDCS of the left DLPFC with $2 \mathrm{~mA}$. The other conditions of stimulation (sham tDCS, anodal tDCS of the left DLPFC with $1 \mathrm{~mA}$, or anodal tDCS of the M1) did not result in a significant task performance change. These results suggest not only site specificity but also dose specificity ( $1 \mathrm{~mA} v s 2 \mathrm{~mA})$.

Although tDCS also seems to induce beneficial effects in PD, further studies are needed to replicate these results, to determine duration of benefits, and to assess effects under different contexts (e.g., on $v s$ off medication).

\section{DYSTONIA}

Dystonia refers to a syndrome of sustained involuntary muscle contractions that usually produce twisting and repetitive movements or abnormal postures. ${ }^{105}$ Primary dystonia occurs in the absence of other neurological abnormalities and without an identified brain lesion or cause (other than a genetic mutation). Primary dystonia is thought to arise from a functional disturbance of basal ganglia circuits that results in abnormal motor commands. ${ }^{106}$ This abnormal motor output contributes to inappropriate activation of muscle groups, which interferes with voluntary motor control and produces twisted postures of limbs, trunk, or neck. Generalized dystonia can involve the whole body. In contrast, focal dystonia involves abnormal muscle contractions restricted to one part of the body, and can be surprisingly context specific. Writer's cramp is a particular example, in which dystonic postures arise in the affected hand only when writing, not when using hand muscles for other purposes.

Despite dystonia being a widely heterogeneous group of disorders, studies of dystonia pathophysiology and of applications of rTMS and tDCS, have focused largely on upper extremity limb dystonia. Hand dystonia is often easily activated experimentally, and its cortical representation within the contralateral M1 is easily accessible with noninvasive cortical stimulation. Physiologically, the abnormal motor outflow in dystonia corresponds to excess and nonselective muscle activation.

Sensory and sensorimotor integration abnormalities suggest that dystonia pathophysiology is not restricted to the motor system. ${ }^{107}$ These abnormalities may be considered consequences of excess maladaptive plasticity. In this view, the sensorimotor system in dystonia patients is abnormally sensitive to external stimuli and in response may generate inappropriate and nonspecific sensorimotor associations that interfere with context-specific motor actions. ${ }^{8}$ The potential for rTMS and tDCS to downregulate excess plasticity by appropriate cortical neuromodulation provides a theoretical foundation to normalize or correct abnormal dystonic physiology for symptomatic benefit.

\section{Abnormalities of network activation}

Neuroimaging studies have shown consistent abnormalities in limb dystonia patients, distributed within the subcortical and cortical motor system and involving bilateral PMd, primary sensory and motor cortices, and supplementary motor area (SMA). ${ }^{108-111}$ However, as expected with the heterogeneity of dystonia, the degree of activity increase or decrease within cortical regions varies among studies depending on patient variability and differences in imaging protocol and task-activation conditions. In patients with writer's cramp, excess activity is commonly described in the left sensorimotor cortex, PMd, SMA, and cerebellum with dystonia-inducing tasks. ${ }^{109-112}$ In contrast, relative reductions have also been described in the left sensorimotor cortex and PMd during nonspecific and specific activation tasks. ${ }^{113,114}$

Although variable, the predominant pattern in dystonia is one of context-related excess activation of primary sensory, motor, and premotor cortices. These overactivation patterns are often interpreted as loss of specificity in muscle activation, excess maladaptive plasticity in the motor cortex, or increased difficulty of task. These patterns also suggest the M1 and PMd as targets for downregulation by extrinsic rTMS or tDCS neuromodulation.

\section{Abnormalities of excitability}

Dystonia is associated with loss of inhibition at multiple levels of the neuroaxis, including spinal cord, brainstem, and cortex. The excessive and inappropriate muscle activation patterns seen in patients with focal dystonia reflect disinhibition of cortical-subcortical motor circuits, which may be a consequence of abnormalities of sensorimotor integration and maladaptive plasticity.

Among writer's cramp patients, silent periods are shorter, and short-interval intracortical inhibition is reduced, compared with control subjects. ${ }^{115-117}$ This disinhibition can be task-specific within the same hand muscle. ${ }^{118}$ Normal surround inhibition of muscles near the specific muscle intended for movement is impaired in hand dystonia patients. ${ }^{119}$ Treatment with botulinum toxin may transiently normalize intracortical inhibition in association with clinical benefit. ${ }^{33}$ Although disinhibition predominates, context-specific impairment in premovement excitability facilitation has also been de- 
scribed, perhaps explaining bradykinesia of dystonic movement in some patients. ${ }^{120}$

Consistent with altered sensorimotor integration, the normal inhibition of excitability after a peripheral electrical stimulus becomes facilitated in patients with dystonia. ${ }^{121}$ Repeated pairs of peripheral electrical stimulation synchronized with cortical TMS pulses, that normally produce robust facilitation in excitability, resulted in further exaggerated excitability in patients with dystonia. ${ }^{122}$ Similarly, although muscle vibration normally facilitates cortical excitability to that muscle, excitability was suppressed in patients with focal dystonia. ${ }^{123}$ These abnormal responses suggest that maladaptive plasticity may be a fundamental deficit in symptomatic dystonia. ${ }^{124}$

\section{Neuromodulation studies in dystonia}

Downregulation of excess plastic responses in a disorder in which disinhibition predominates can be a challenge. Low-frequency rTMS or cathodal tDCS, which typically reduce excitability in normal subjects, may not necessarily have the same effect in dystonic patients. Several studies, however, have shown the potential for normalization of excitability or of abnormal network patterns with low-frequency rTMS over the M1 or PMd. A few preliminary studies and case reports have also shown some success with these factors (Table 5). Generalization from these studies, and future directions, must take into account the heterogeneity of dystonia and lack of standardized protocols for assessing outcomes. For example, the two controlled studies focused on writer's cramp and analysis of handwriting, ${ }^{117,125}$ whereas the two case reports suggested different patterns of benefit (pain ${ }^{126}$ and neck dystonia ${ }^{127}$ ) on patients with different dystonia diagnoses.

Motor cortex stimulation. Consistent with maladaptive plasticity in dystonia, motor cortex excitability often responds inappropriately, often with disinhibition, after a train of rTMS. After several trains of suprathreshold 1-Hz rTMS over the M1, cortical excitability was suppressed in control subjects, but facilitated in writer's cramp patients. ${ }^{128}$ With much lower thresholds, 1-Hz rTMS over the M1 did not alter any several measures of excitability in focal hand dystonia patients, even though excitability in control subjects was reduced. ${ }^{129}$ Brief trains of up to 20 pulses of suprathreshold $1 \mathrm{~Hz}$ did not alter excitability, but at $5 \mathrm{~Hz}$ it resulted in an exaggerated, and longer-lived, excitability facilitation, compared with control subjects. ${ }^{130}$

Cathodal tDCS suppresses excitability in control subjects, but tends to increase excitability in dystonia patients. Furthermore, in control subjects, 1-Hz rTMS over the M1 after priming by excitatory anodal tDCS, also uniformly reduced excitability. In contrast, dystonia patients had no consistent effect with rTMS, regardless of preceding anodal or cathodal tDCS. ${ }^{131}$ These results

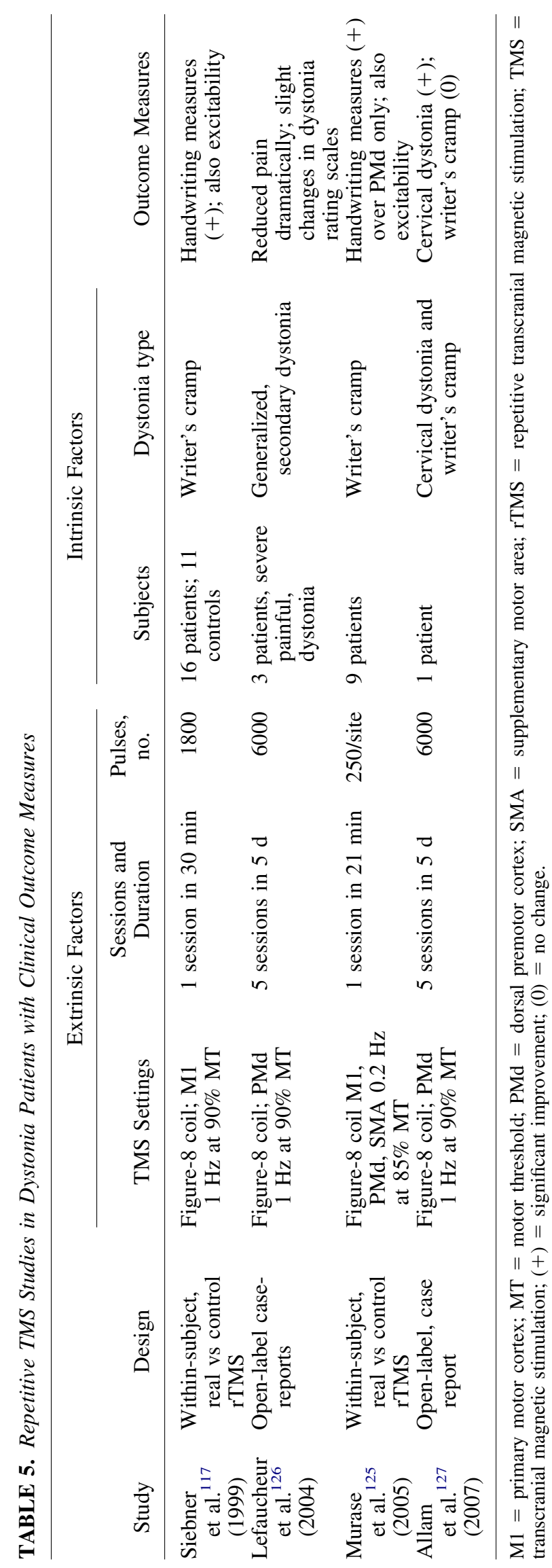

Neurotherapeutics, Vol. 5, No. 2, 2008 
were interpreted as a disruption of normal homeostatic regulation of excitability in response to external tDCS and rTMS stimulation. This study also suggests that these rTMS and tDCS factors may not easily restore normal mechanisms of plasticity.

Nonetheless, one study has suggested some clinical benefit in dystonia patients after low-frequency rTMS over the M1 in association with normalization of this abnormal disinhibition. ${ }^{117}$ Among writer's cramp patients, single-sessions of subthreshold 1-Hz rTMS over the M1 normalized intracortical inhibition and also prolonged silent periods. Patients showed a benefit in mean writing pressure, with several patients showing clear improvements in handwriting. The normalization of excitability by rTMS in this study are in contrast with other studies, which showed either facilitation or no change in excitability in dystonia patients after 1-Hz rTMS. ${ }^{128,129}$ Variation in intensity and excitability measures, and in study design, may account for these differences; replication would be of interest.

Dorsal premotor cortex stimulation. The PMd has dense reciprocal connections with both M1 and SMA within the abnormal dystonic cortical network. As with the M1, rTMS over the PMd can modulate M1 excitability bidirectionally, with low frequencies suppressing and high frequencies enhancing excitability. ${ }^{132}$ However, rTMS effects over the PMd can induce lasting effects on cortical excitability, often to a greater degree than with rTMS over the M1 itself. ${ }^{133}$ With PET scanning, subthreshold 1-Hz rTMS over the left PMd was shown to reduce rCBF in the left sensorimotor cortex, left PMd, SMA, and cerebellum both in normal control subjects and in patients with focal dystonia. ${ }^{24}$ However, the decrease was significantly greater among patients in bilateral PMd, SMA, and precuneus. Findings support the use of $1-\mathrm{Hz}$ rTMS over the PMd to effect widespread inhibitory effects throughout the motor network in dystonia patients. We note that $1-\mathrm{Hz}$ rTMS over the PMd also normalizes spinal reflexes that are abnormal in patients with DYT1 generalized dystonia. ${ }^{134}$ Therefore, effects of rTMS over the PMd extend down the neuroaxis and provide evidence that modulation at this cortical site can normalize sensorimotor integration at multiple neuroanatomic levels.

Testing low-intensity $0.2-\mathrm{Hz}$ rTMS over the M1, SMA, and PMd in separate sessions with writer's cramp patients, Murase et al. ${ }^{125}$ found that only stimulation over the PMd site prolonged silent periods and improved handwriting. Two open case study reports reported effects of five daily sessions of $1-\mathrm{Hz}$ rTMS over the left PMd. After rTMS, three patients with severe, generalized, secondary dystonia showed reduced painful axial spasms, but less consistent reductions of abnormal movements or disability. ${ }^{126}$ In the other case, a patient with primary dystonia affecting neck and limb showed improvement of neck, but not limb, dystonia symptoms after rTMS sessions. ${ }^{127}$ These studies provide encouraging data in support of the use of multisession
rTMS over the PMd to modulate dystonia. However, the topographic nature of rTMS modulation over the left PMd and the relationship between rTMS and pain or disability in these patients remain to be clarified.

\section{CONCLUSION}

In conclusion, rTMS and tDCS are promising noninvasive cortical stimulation tools that may provide a future option for adjunctive therapy in PD, dystonia, and other movement disorders. Although the studies with clinical outcomes reviewed here show the potential for benefit, many are small studies that span a large range of intrinsic and extrinsic factors. For now, it remains unclear whether rTMS or tDCS have beneficial effects on PD or dystonia, and neither modulatory technique has established protocols to assure the predictable long-term effects on clinical outcome measures that are needed to establish a clinically relevant role in treatment. Future controlled studies, focusing on selected extrinsic and intrinsic factors, can provide evidence for potentially spatially specific and symptom-specific roles for rTMS and tDCS. Studies that include functional neuroimaging or cortical excitability outcome measures will add to the accumulating evidence for rational mechanisms of rTMS and tDCS effects.

Acknowledgments: This work was supported by U.S. National Institutes of Health (NIH) grant K24 RR018875 and a BBVA Foundation Translational Research Chair to A.P.L., the Harvard Medical School Scholars in Clinical Sciences Program (NIH K30 HL004095-03) to F.F., and NIH grant (K23 NS045764) to A.D.W.

\section{REFERENCES}

1. Mink JW. The basal ganglia and involuntary movements: impaired inhibition of competing motor patterns. Arch Neurol 2003; 60:1365-1368.

2. Pahwa R, Factor SA, Lyons KE, et al. Practice Parameter: treatment of Parkinson disease with motor fluctuations and dyskinesia (an evidence-based review): report of the Quality Standards Subcommittee of the American Academy of Neurology. Neurology 2006;66:983-995.

3. Jankovic J. Treatment of dystonia. Lancet Neurol 2006;5:864872 .

4. Weintraub D, Moberg PJ, Duda JE, Katz IR, Stern MB. Effect of psychiatric and other nonmotor symptoms on disability in Parkinson's disease. J Am Geriatr Soc 2004;52:784-788.

5. Skidmore FM, Rodriguez RL, Fernandez HH, Goodman WK, Foote KD, Okun MS. Lessons learned in deep brain stimulation for movement and neuropsychiatric disorders. CNS Spectr 2006; 11:521-536.

6. Albanese A, Barnes MP, Bhatia KP, et al. A systematic review on the diagnosis and treatment of primary (idiopathic) dystonia and dystonia plus syndromes: report of an EFNS/MDS-ES Task Force. Eur J Neurol 2006;13:433-444.

7. Wagner T, Valero-Cabre A, Pascual-Leone A. Noninvasive human brain stimulation. Annu Rev Biomed Eng 2007;9:527-565.

8. Quartarone A, Siebner HR, Rothwell JC. Task-specific hand dystonia: can too much plasticity be bad for you? Trends Neurosci 2006;29:192-199.

9. Brasil-Neto JP, Cohen LG, Panizza M, Nilsson J, Roth BJ, Hallett M. Optimal focal transcranial magnetic activation of the human motor cortex: effects of coil orientation, shape of the induced 
current pulse, and stimulus intensity. J Clin Neurophysiol 1992;9:132-136.

10. Romero JR, Anschel D, Sparing R, Gangitano M, Pascual-Leone A. Subthreshold low frequency repetitive transcranial magnetic stimulation selectively decreases facilitation in the motor cortex. Clin Neurophysiol 2002;113:101-107.

11. Peinemann A, Reimer B, Loer C, et al. Long-lasting increase in corticospinal excitability after 1800 pulses of subthreshold $5 \mathrm{~Hz}$ repetitive TMS to the primary motor cortex. Clin Neurophysiol 2004;115:1519-1526.

12. Nitsche MA, Liebetanz D, Antal A, Lang N, Tergau F, Paulus W. Modulation of cortical excitability by weak direct current stimulation: technical, safety and functional aspects. Suppl Clin Neurophysiol 2003;56:255-276.

13. Helmich RC, Siebner HR, Bakker M, Münchau A, Bloem BR Repetitive transcranial magnetic stimulation to improve mood and motor function in Parkinson's disease. J Neurol Sci 2006; 248:84-96.

14. Pascual-Leone A, Valls-Solé J, Wassermann EM, Hallett M. Responses to rapid-rate transcranial magnetic stimulation of the human motor cortex. Brain 1994;117:847-858.

15. Chen R, Classen J, Gerloff C, et al. Depression of motor cortex excitability by low-frequency transcranial magnetic stimulation. Neurology 1997;48:1398-1403.

16. Touge T, Gerschlager W, Brown P, Rothwell JC. Are the aftereffects of low-frequency rTMS on motor cortex excitability due to changes in the efficacy of cortical synapses? Clin Neurophysiol 2001;112:2138-2145.

17. Fitzgerald PB, Brown TL, Daskalakis ZJ, Chen R, Kulkarni J. Intensity-dependent effects of $1 \mathrm{~Hz}$ rTMS on human corticospinal excitability. Clin Neurophysiol 2002;113:1136-1141.

18. Antal A, Nitsche MA, Paulus W. External modulation of visual perception in humans. Neuroreport 2001;12:3553-3555.

19. Nitsche MA, Paulus W. Excitability changes induced in the human motor cortex by weak transcranial direct current stimulation. J Physiol 2000;527:633-639.

20. Nitsche MA, Paulus W. Sustained excitability elevations induced by transcranial DC motor cortex stimulation in humans. Neurology 2001;57:1899-1901.

21. Wang H, Wang X, Scheich H. LTD and LTP induced by transcranial magnetic stimulation in auditory cortex. Neuroreport 1996;7:521-525.

22. Stefan K, Kunesch E, Benecke R, Cohen LG, Classen J. Mechanisms of enhancement of human motor cortex excitability induced by interventional paired associative stimulation. J Physiol 2002;543:699-708.

23. Baumer T, Demiralay C, Hidding U, et al. Abnormal plasticity of the sensorimotor cortex to slow repetitive transcranial magnetic stimulation in patients with writer's cramp. Mov Disord 2007;22: 81-90.

24. Siebner HR, Filipovic SR, Rowe JB, et al. Patients with focal arm dystonia have increased sensitivity to slow-frequency repetitive TMS of the dorsal premotor cortex. Brain 2003;126:2710-2725.

25. Buhmann C, Gorsler A, Bäumer T, et al. Abnormal excitability of premotor-motor connections in de novo Parkinson's disease. Brain 2004;127:2732-2746.

26. Lomarev MP, Kanchana S, Bara-Jimenez W, Iyer M, Wassermann EM, Hallett M. Placebo-controlled study of rTMS for the treatment of Parkinson's disease. Mov Disord 2006;21:325-331.

27. Khedr EM, Farweez HM, Islam H. Therapeutic effect of repetitive transcranial magnetic stimulation on motor function in Parkinson's disease patients. Eur J Neurol 2003;10:567-572.

28. Fregni F, Ono CR, Santos CM, et al. Effects of antidepressant treatment with rTMS and fluoxetine on brain perfusion in PD. Neurology 2006;66:1629-1637.

29. Maeda F, Keenan JP, Tormos JM, Topka H, Pascual-Leone A. Interindividual variability of the modulatory effects of repetitive transcranial magnetic stimulation on cortical excitability. Exp Brain Res 2000;133:425-430.

30. Kleim JA, Chan S, Pringle E, et al. BDNF val66met polymorphism is associated with modified experience-dependent plasticity in human motor cortex. Nat Neurosci 2006;9:735-737.
31. Gilio F, Currà A, Inghilleri M, Lorenzano C, Manfredi M, Berardelli A. Repetitive magnetic stimulation of cortical motor areas in Parkinson's disease: implications for the pathophysiology of cortical function. Mov Disord 2002;17:467-473.

32. Fierro B, Brighina F, D'Amelio M, et al. Motor intracortical inhibition in PD: L-DOPA modulation of high-frequency rTMS effects. Exp Brain Res 2008;184:521-528.

33. Gilio F, Currà A, Lorenzano C, Modugno N, Manfredi M, Berardelli A. Effects of botulinum toxin type A on intracortical inhibition in patients with dystonia. Ann Neurol 2000;48:20-26.

34. Fregni F, Pascual-Leone A. Technology insight: noninvasive brain stimulation in neurology: perspectives on the therapeutic potential of rTMS and tDCS. Nat Clin Pract Neurol 2007;3:383393.

35. Hallett M. Transcranial magnetic stimulation: a primer. Neuron 2007;55:187-199.

36. Ziemann U. TMS and drugs. Clin Neurophysiol 2004;115:17171729.

37. Werhahn KJ, Kunesch E, Noachtar S, Benecke R, Classen J. Differential effects on motorcortical inhibition induced by blockade of GABA uptake in humans. J Physiol 1999;517:591-597.

38. Di Lazzaro V, Oliviero A, Meglio M, et al. Direct demonstration of the effect of lorazepam on the excitability of the human motor cortex. Clin Neurophysiol 2000;111:794-799.

39. Paus T, Castro-Alamancos MA, Petrides M. Cortico-cortical connectivity of the human mid-dorsolateral frontal cortex and its modulation by repetitive transcranial magnetic stimulation. Eur J Neurosci 2001;14:1405-1411.

40. Lang N, Siebner HR, Ward NS, et al. How does transcranial DC stimulation of the primary motor cortex alter regional neuronal activity in the human brain? Eur J Neurosci 2005;22:495-504.

41. van Eimeren T, Siebner HR. An update on functional neuroimaging of parkinsonism and dystonia. Curr Opin Neurol 2006;19: 412-419.

42. Siebner HR, Peller M, Willoch F, et al. Lasting cortical activation after repetitive TMS of the motor cortex: a glucose metabolic study. Neurology 2000;54:956-963.

43. Rounis E, Lee L, Siebner HR, et al. Frequency specific changes in regional cerebral blood flow and motor system connectivity following rTMS to the primary motor cortex. Neuroimage 2005; 26:164-176.

44. Strafella AP, Paus T, Barrett J, Dagher A. Repetitive transcranial magnetic stimulation of the human prefrontal cortex induces dopamine release in the caudate nucleus. J Neurosci 2001;21: RC157.

45. Strafella AP, Paus T, Fraraccio M, Dagher A. Striatal dopamine release induced by repetitive transcranial magnetic stimulation of the human motor cortex. Brain 2003;126:2609-2615.

46. Koch G, Brusa L, Caltagirone C, et al. rTMS of supplementary motor area modulates therapy-induced dyskinesias in Parkinson disease. Neurology 2005;65:623-625.

47. Fregni F, Boggio PS, Bermpohl F, et al. Immediate placebo effect in Parkinson's disease: is the subjective relief accompanied by objective improvement? Eur Neurol 2006;56:222-229.

48. de la Fuente-Fernandez R. Uncovering the hidden placebo effect in deep-brain stimulation for Parkinson's disease. Parkinsonism Relat Disord 2004;10:125-127.

49. Loo CK, Taylor JL, Gandevia SC, McDarmont BN, Mitchell PB, Sachdev PS. Transcranial magnetic stimulation (TMS) in controlled treatment studies: are some "sham" forms active? Biol Psychiatry 2000;47:325-331.

50. Gandiga PC, Hummel FC, Cohen LG. Transcranial DC stimulation (tDCS): a tool for double-blind sham-controlled clinical studies in brain stimulation. Clin Neurophysiol 2006;117:845-850.

51. Wassermann EM. Risk and safety of repetitive transcranial magnetic stimulation: report and suggested guidelines from the International Workshop on the Safety of Repetitive Transcranial Magnetic Stimulation, June 5-7, 1996. Electroencephalogr Clin Neurophysiol 1998;108:1-16.

52. Belmaker B, Fitzgerald P, George MS, et al. Managing the risks of repetitive transcranial stimulation. CNS Spectr 2003;8:489.

53. Machii K, Cohen D, Ramos-Estebanez C, Pascual-Leone A 
Safety of rTMS to non-motor cortical areas in healthy participants and patients. Clin Neurophysiol 2006;117:455-471.

54. Boylan LS, Pullman SL, Lisanby SH, Spicknall KE, Sackeim HA. Repetitive transcranial magnetic stimulation to SMA worsens complex movements in Parkinson's disease. Clin Neurophysiol 2001;112:259-264.

55. Huang YZ, Edwards MJ, Rounis E, Bhatia KP, Rothwell JC. Theta burst stimulation of the human motor cortex. Neuron 2005; 45:201-206.

56. Braak H, Ghebremedhin E, Rüb U, Bratzke H, Del Tredici K. Stages in the development of Parkinson's disease-related pathology. Cell Tissue Res 2004;318:121-134.

57. Lefaucheur JP. Motor cortex dysfunction revealed by cortical excitability studies in Parkinson's disease: influence of antiparkinsonian treatment and cortical stimulation. Clin Neurophysiol 2005;116:244-253.

58. Grafton ST. Contributions of functional imaging to understanding parkinsonian symptoms. Curr Opin Neurobiol 2004;14:715-719.

59. Strafella AP, Ko JH, Grant J, Fraraccio M, Monchi O. Corticostriatal functional interactions in Parkinson's disease: a rTMS/ $\left[{ }^{11}\right.$ C]raclopride PET study. Eur J Neurosci 2005;22:2946-2952.

60. Strafella AP, Ko JH, Monchi O. Therapeutic application of transcranial magnetic stimulation in Parkinson's disease: the contribution of expectation. Neuroimage 2006;31:1666-1672.

61. Shimamoto H, Takasaki K, Shigemori M, Imaizumi T, Ayabe M, Shoji $\mathrm{H}$. Therapeutic effect and mechanism of repetitive transcranial magnetic stimulation in Parkinson's disease. J Neurol 2001;248 Suppl 3:III48-III52.

62. Parkinson Study Group. Cerebrospinal fluid homovanillic acid in the DATATOP study on Parkinson's disease. Arch Neurol 1995; 52:237-245.

63. Khedr EM, Rothwell JC, Shawky OA, Ahmed MA, Foly N, Hamdy A. Dopamine levels after repetitive transcranial magnetic stimulation of motor cortex in patients with Parkinson's disease: preliminary results. Mov Disord 2007;22:1046-1050.

64. Haslinger B, Erhard P, Kampfe N, et al. Event-related functional magnetic resonance imaging in Parkinson's disease before and after levodopa. Brain 2001;124:558-570.

65. Sabatini U, Boulanouar K, Fabre N, et al. Cortical motor reorganization in akinetic patients with Parkinson's disease: a functional MRI study. Brain 2000;123:394-403.

66. Berardelli A, Rothwell JC, Thompson PD, Hallett M. Pathophysiology of bradykinesia in Parkinson's disease. Brain 2001;124: 2131-2146.

67. Grafton ST, Turner RS, Desmurget M, et al. Normalizing motorrelated brain activity: subthalamic nucleus stimulation in Parkinson disease. Neurology 2006;66:1192-1199.

68. Cantello R, Gianelli M, Bettucci D, Civardi C, De Angelis MS, Mutani R. Parkinson's disease rigidity: magnetic motor evoked potentials in a small hand muscle. Neurology 1991;41:14491456.

69. Valls-Solé J, Pascual-Leone A, Brasil-Neto JP, Cammarota A, McShane L, Hallett M. Abnormal facilitation of the response to transcranial magnetic stimulation in patients with Parkinson's disease. Neurology 1994;44:735-741.

70. Chen R, Kumar S, Garg RR, Lang AE. Impairment of motor cortex activation and deactivation in Parkinson's disease. Clin Neurophysiol 2001;112:600-607.

71. Wu AD, Petzinger GM, Lin CH, Kung M, Fisher B. Asymmetric corticomotor excitability correlations in early Parkinson's disease. Mov Disord 2007;22:1587-1593.

72. Priori A, Berardelli A, Inghilleri M, Accornero N, Manfredi M. Motor cortical inhibition and the dopaminergic system: pharmacological changes in the silent period after transcranial brain stimulation in normal subjects, patients with Parkinson's disease and drug-induced parkinsonism. Brain 1994;117:317-323.

73. Chen R, Garg RR, Lozano AM, Lang AE. Effects of internal globus pallidus stimulation on motor cortex excitability. Neurology 2001;56:716-723.

74. Ellaway PH, Davey NJ, Maskill DW, Dick JP. The relation between bradykinesia and excitability of the motor cortex assessed using transcranial magnetic stimulation in normal and parkinsonian subjects. Electroencephalogr Clin Neurophysiol 1995;97:169-178.

75. Málly J, Farkas R, Tóthfalusi L, Stone TW. Long-term follow-up study with repetitive transcranial magnetic stimulation (rTMS) in Parkinson's disease. Brain Res Bull 2004;64:259-263.

76. Dragaševic N, Potrebić A, Damjanović A, Stefanova E, Kostić VS. Therapeutic efficacy of bilateral prefrontal slow repetitive transcranial magnetic stimulation in depressed patients with Parkinson's disease: an open study. Mov Disord 2002;17:528-532.

77. Okabe S, Hanajima R, Ohnishi T, et al. Functional connectivity revealed by single-photon emission computed tomography (SPECT) during repetitive transcranial magnetic stimulation (rTMS) of the motor cortex. Clin Neurophysiol 2003;114:450 457.

78. Fregni F, Santos CM, Myczkowski ML, et al. Repetitive transcranial magnetic stimulation is as effective as fluoxetine in the treatment of depression in patients with Parkinson's disease. J Neurol Neurosurg Psychiatry 2004;75:1171-1174.

79. Epstein CM, Evatt ML, Funk A, et al. An open study of repetitive transcranial magnetic stimulation in treatment-resistant depression with Parkinson's disease. Clin Neurophysiol 2007;118:2189-2194.

80. Brusa L, Versace V, Koch G, et al. Low frequency rTMS of the SMA transiently ameliorates peak-dose LID in Parkinson's disease. Clin Neurophysiol 2006;117:1917-1921.

81. Tergau F, Wassermann EM, Paulus W, Ziemann U. Lack of clinical improvement in patients with Parkinson's disease after low and high frequency repetitive transcranial magnetic stimulation. Electroencephalogr Clin Neurophysiol Suppl 1999;51:281288.

82. Okabe S, Ugawa Y, Kanazawa I. 0.2-Hz repetitive transcranial magnetic stimulation has no add-on effects as compared to a realistic sham stimulation in Parkinson's disease. Mov Disord 2003; 18:382-388

83. Mir P, Matsunaga K, Gilio F, Quinn NP, Siebner HR, Rothwell JC. Dopaminergic drugs restore facilitatory premotor-motor interactions in Parkinson disease. Neurology 2005;64:1906-1912.

84. Fregni F, Simon DK, Wu A, Pascual-Leone A. Non-invasive brain stimulation for Parkinson's disease: a systematic review and meta-analysis of the literature. J Neurol Neurosurg Psychiatry 2005; 76:1614-1623.

85. Pascual-Leone A, Valls-Solé J, Brasil-Neto JP, Cammarota A, Grafman J, Hallett M. Akinesia in Parkinson's disease. II. Effects of subthreshold repetitive transcranial motor cortex stimulation. Neurology 1994;44:892-898.

86. Ghabra MB, Hallett M, Wassermann EM. Simultaneous repetitive transcranial magnetic stimulation does not speed fine movement in PD. Neurology 1999;52:768-770.

87. Siebner HR. Simultaneous repetitive transcranial magnetic stimulation does not speed fine movement in PD [Comment on: Neurology 1999;52:768-770]. Neurology 2000;54:272; author reply 273 .

88. Siebner HR, Mentschel C, Auer C, Lehner C, Conrad B. Repetitive transcranial magnetic stimulation causes a short-term increase in the duration of the cortical silent period in patients with Parkinson's disease. Neurosci Lett 2000;284:147-150.

89. Siebner HR, Rossmeier C, Mentschel C, Peinemann A, Conrad B. Short-term motor improvement after sub-threshold $5-\mathrm{Hz}$ repetitive transcranial magnetic stimulation of the primary motor hand area in Parkinson's disease. J Neurol Sci 2000;178:91-94.

90. Siebner HR, Mentschel C, Auer C, Conrad B. Repetitive transcranial magnetic stimulation has a beneficial effect on bradykinesia in Parkinson's disease. Neuroreport 1999;10:589-594.

91. Lefaucheur JP, Drouot X, Von Raison F, Ménard-Lefaucheur I, Cesaro P, Nguyen JP. Improvement of motor performance and modulation of cortical excitability by repetitive transcranial magnetic stimulation of the motor cortex in Parkinson's disease. Clin Neurophysiol 2004;115:2530-2541.

92. Börnke C, Schulte T, Przuntek H, Müller T. Clinical effects of repetitive transcranial magnetic stimulation versus acute levodopa challenge in Parkinson's disease. J Neural Transm Suppl 2004:61-67.

93. Khedr EM, Rothwell JC, Shawky OA, Ahmed MA, Hamdy A. Effect of daily repetitive transcranial magnetic stimulation on 
motor performance in Parkinson's disease. Mov Disord 2006; 21:2201-2205.

94. Ikeguchi M, Touge T, Nishiyama Y, Takeuchi H, Kuriyama S, Ohkawa M. Effects of successive repetitive transcranial magnetic stimulation on motor performances and brain perfusion in idiopathic Parkinson's disease. J Neurol Sci 2003;209:41-46.

95. Shimamoto H, Morimitsu H, Sugita S, Nakahara K, Shigemori M. Therapeutic effect of repetitive transcranial magnetic stimulation in Parkinson's disease. Rinsho Shinkeigaku 1999;39:1264-1267.

96. del Olmo MF, Bello O, Cudeiro J. Transcranial magnetic stimulation over dorsolateral prefrontal cortex in Parkinson's disease. Clin Neurophysiol 2007;118:131-139.

97. Dias AE, Barbosa ER, Coracini K, Maia F, Marcolin MA, Fregni F. Effects of repetitive transcranial magnetic stimulation on voice and speech in Parkinson's disease. Acta Neurol Scand 2006;113: 92-99.

98. Cardoso EF, Fregni F, Martins Maia F, et al. rTMS treatment for depression in Parkinson's disease increases BOLD responses in the left prefrontal cortex. Int J Neuropsychopharmacol 2007:111 .

99. Turner RS, Grafton ST, McIntosh AR, DeLong MR, Hoffman JM. The functional anatomy of parkinsonian bradykinesia. Neuroimage 2003;19:163-179.

100. Brooks DJ, Piccini P, Turjanski N, Samuel M. Neuroimaging of dyskinesia. Ann Neurol 2000;47:S154-S158; discussion S158S159.

101. Rascol O, Sabatini U, Brefel C, et al. Cortical motor overactivation in parkinsonian patients with L-dopa-induced peak-dose dyskinesia. Brain 1998;121:527-533.

102. Fregni F, Boggio PS, Santos MC, et al. Noninvasive cortical stimulation with transcranial direct current stimulation in Parkinson's disease. Mov Disord 2006;21:1693-1702.

103. Nitsche MA, Seeber A, Frommann K, et al. Modulating parameters of excitability during and after transcranial direct current stimulation of the human motor cortex. J Physiol 2005;568:291303.

104. Boggio PS, Ferrucci R, Rigonatti SP, et al. Effects of transcranial direct current stimulation on working memory in patients with Parkinson's disease. J Neurol Sci 2006;249:31-38.

105. Fahn S, Bressman SB, Marsden CD. Classification of dystonia. Adv Neurol 1998:78:1-10.

106. Berardelli A, Rothwell JC, Hallett M, Thompson PD, Manfredi $\mathrm{M}$, Marsden $\mathrm{CD}$. The pathophysiology of primary dystonia. Brain 1998;121:1195-1212.

107. Hallett M. Pathophysiology of dystonia. J Neural Transm Suppl 2006:485-488.

108. Ceballos-Baumann AO, Brooks DJ. Basal ganglia function and dysfunction revealed by PET activation studies. Adv Neurol 1997;74:127-139.

109. Lerner A, Shill H, Hanakawa T, Bushara K, Goldfine A, Hallett M. Regional cerebral blood flow correlates of the severity of writer's cramp symptoms. Neuroimage 2004;21:904-913.

110. Hu XY, Wang L, Liu H, Zhang SZ. Functional magnetic resonance imaging study of writer's cramp. Chin Med J (Engl) 2006; 119:1263-1271.

111. Preibisch C, Berg D, Hofmann E, Solymosi L, Naumann M. Cerebral activation patterns in patients with writer's cramp: a functional magnetic resonance imaging study. J Neurol 2001;248: $10-17$.

112. Odergren T, Stone-Elander S, Ingvar M. Cerebral and cerebellar activation in correlation to the action-induced dystonia in writer's cramp. Mov Disord 1998;13:497-508.

113. Ibáñez V, Sadato N, Karp B, Deiber MP, Hallett M. Deficient activation of the motor cortical network in patients with writer's cramp. Neurology 1999;53:96-105.

114. Oga T, Honda M, Toma K, et al. Abnormal cortical mechanisms of voluntary muscle relaxation in patients with writer's cramp: an fMRI study. Brain 2002;125:895-903.

115. Filipović SR, Ljubisavljević M, Svetel M, Milanović S, Kacar A, Kostić VS. Impairment of cortical inhibition in writer's cramp as revealed by changes in electromyographic silent period after transcranial magnetic stimulation. Neurosci Lett 1997;222:167170 .
116. Ridding MC, Sheean G, Rothwell JC, Inzelberg R, Kujirai T. Changes in the balance between motor cortical excitation and inhibition in focal, task specific dystonia. J Neurol Neurosurg Psychiatry 1995;59:493-498.

117. Siebner HR, Tormos JM, Ceballos-Baumann AO, et al. Lowfrequency repetitive transcranial magnetic stimulation of the motor cortex in writer's cramp. Neurology 1999;52:529-537.

118. Tinazzi M, Farina S, Edwards M, et al. Task-specific impairment of motor cortical excitation and inhibition in patients with writer's cramp. Neurosci Lett 2005;378:55-58.

119. Sohn YH, Hallett M. Disturbed surround inhibition in focal hand dystonia. Ann Neurol 2004;56:595-599.

120. Gilio $\mathrm{F}$, Currà $\mathrm{A}$, Inghilleri $\mathrm{M}$, et al. Abnormalities of motor cortex excitability preceding movement in patients with dystonia. Brain 2003;126:1745-1754.

121. Kessler KR, Ruge D, Ilić TV, Ziemann U. Short latency afferent inhibition and facilitation in patients with writer's cramp. Mov Disord 2005;20:238-242.

122. Quartarone A, Bagnato S, Rizzo V, et al. Abnormal associative plasticity of the human motor cortex in writer's cramp. Brain 2003; 126:2586-2596.

123. Rosenkranz K, Altenmüller E, Siggelkow S, Dengler R. Alteration of sensorimotor integration in musician's cramp: impaired focusing of proprioception. Clin Neurophysiol 2000;111:2040 2045.

124. Edwards MJ, Huang YZ, Mir P, Rothwell JC, Bhatia KP. Abnormalities in motor cortical plasticity differentiate manifesting and nonmanifesting DYT1 carriers. Mov Disord 2006;21:21812186.

125. Murase N, Rothwell JC, Kaji R, et al. Subthreshold low-frequency repetitive transcranial magnetic stimulation over the premotor cortex modulates writer's cramp. Brain 2005;128:104115.

126. Lefaucheur JP, Fénelon G, Ménard-Lefaucheur I, Wendling S, Nguyen JP. Low-frequency repetitive TMS of premotor cortex can reduce painful axial spasms in generalized secondary dystonia: a pilot study of three patients. Neurophysiol Clin 2004;34: 141-145.

127. Allam N, Brasil-Neto JP, Brandao P, Weiler F, Barros Filho J, Tomaz C. Relief of primary cervical dystonia symptoms by low frequency transcranial magnetic stimulation of the premotor cortex: case report. Arq Neuropsiquiatr 2007;65:697-699.

128. Siebner HR, Auer C, Conrad B. Abnormal increase in the corticomotor output to the affected hand during repetitive transcranial magnetic stimulation of the primary motor cortex in patients with writer's cramp. Neurosci Lett 1999;262:133-136.

129. Stinear CM, Byblow WD. Impaired modulation of corticospinal excitability following subthreshold rTMS in focal hand dystonia. Hum Mov Sci 2004;23:527-538.

130. Gilio F, Suppa A, Bologna M, Lorenzano C, Fabbrini G, Berardelli A. Short-term cortical plasticity in patients with dystonia: a study with repetitive transcranial magnetic stimulation. Mov Disord 2007;22:1436-1443.

131. Quartarone A, Rizzo V, Bagnato S, et al. Homeostatic-like plasticity of the primary motor hand area is impaired in focal hand dystonia. Brain 2005;128:1943-1950.

132. Rizzo V, Siebner HR, Modugno N, et al. Shaping the excitability of human motor cortex with premotor rTMS. J Physiol 2004;554: 483-495.

133. Gerschlager W, Siebner HR, Rothwell JC. Decreased corticospinal excitability after subthreshold $1 \mathrm{~Hz}$ rTMS over lateral premotor cortex. Neurology 2001;57:449-455.

134. Huang YZ, Edwards MJ, Bhatia KP, Rothwell JC. One-Hz repetitive transcranial magnetic stimulation of the premotor cortex alters reciprocal inhibition in DYT1 dystonia. Mov Disord 2004; 19:54-59.

135. Málly J, Stone TW. Improvement in parkinsonian symptoms after repetitive transcranial magnetic stimulation. J Neurol Sci 1999; 162:179-184.

136. Málly J, Stone TW. Therapeutic and "dose-dependent" effect of repetitive microelectroshock induced by transcranial magnetic stimulation in Parkinson's disease. J Neurosci Res 1999;57:935940. 